\title{
Effect of small-scale heterogeneity on biopolymer performance in carbonates
}

\author{
Emad W. Al-Shalabi ${ }^{1}$ (1)
}

Received: 18 January 2020 / Accepted: 30 June 2020 / Published online: 4 July 2020

(c) The Author(s) 2020

\begin{abstract}
Polymer flooding is a well-established chemical method for enhancing oil recovery in sandstones; however, it has a limited application in carbonates. This is due to the harsh reservoir conditions in carbonates including high temperature, high salinity, and high heterogeneity with low permeability. This paper numerically investigates the effect of Schizophyllan biopolymer on oil recovery from carbonates. The effect of biopolymer on oil recovery was predicted by running several 1D simulations. Biopolymer flow behavior was modeled based on experimental data. The results showed that the effect of the investigated biopolymer on oil recovery was not much pronounced compared to conventional waterflooding. This is due to small-scale heterogeneity, which increased effective shear rate and hence, decreased in-situ polymer viscosity. Formation permeability, polymer viscosity, and oil saturation maps were consistent in justifying this observation. The findings of this study were supported by fractional flow and mobility ratio analyses. This work highlights the importance of small-scale heterogeneity of the core in modeling polymer flooding, particularly the shear effect on polymer viscosity.
\end{abstract}

Keywords Biopolymer modeling $\cdot$ Chemical enhanced oil recovery $($ CEOR) $\cdot$ Small scale heterogeneity $\cdot$ Mobility ratio $\cdot$ Fractional flow analysis

\section{Introduction and background}

A large fraction of original oil in place (OOIP) remains trapped in the reservoir after both primary and secondary recoveries. The latter necessitates the need for enhanced oil recovery (EOR) techniques to improve the oil recovery in an economic way under certain market and technology conditions (Lake 1989). Different EOR techniques are being used including solvents, chemical flooding, thermal methods, and others (Al-Shalabi et al. 2015; Al-Shalabi and Sepehrnoori 2016, 2017).

Polymer flooding is a widely used chemical EOR technique that has been studied and practiced for many years (Chang 1978). In this technique, polymers are added to the water in order to increase its viscosity and hence, improve water sweep efficiency through decreasing the mobility ratio between the displacing fluid (water) and the displaced fluid

Emad W. Al-Shalabi

emad.walshalabi@ku.ac.ae

$1 \quad$ Petroleum Engineering Department, Khalifa University of Science and Technology, Sas Al Nakhl Campus, Abu Dhabi, United Arab Emirates (oil). Consequently, this viscous water dampens viscous fingering effects and results in better volumetric sweep efficiency (Sorbie 1991). This paper discusses in particular, the application of "biopolymer" flooding as an EOR technique on oil recovery from "carbonate" reservoirs under "harsh" conditions.

\section{Carbonates under harsh conditions}

More than half of the world's hydrocarbon proven reserves are present in carbonate reservoirs. The majority of these reservoirs have a complex nature that leads to low oil recovery (about $30 \%$ in average) including both primary and secondary recovery stages. The complexity of these reservoirs includes high temperature (above $80^{\circ} \mathrm{C}$ ), high formation water salinity (TDS above 60,000 ppm), presence of divalent cations (hardness), low permeability (less than $100 \mathrm{mD}$ ), and the wetting nature (about $90 \%$ are mixed-to-oil wet) (Austad et al. 2008; Chandrasekhar and Mohanty 2013; Adegbite et al. 2018; Diab and Al-Shalabi 2019). The low recovery in carbonate reservoirs assures higher potential for enhanced oil recovery (EOR). 


\section{Biopolymer types}

Two main types of polymers are generally used for EOR purposes including synthetically produced partially hydrolyzed polyacrylamides (HPAM) and biologically produced polysaccharides such as Xanthan biopolymers. Polyacrylamides have long molecules with small effective diameters, which results in a high sensitivity to mechanical degradation and consequent viscosity reduction. In addition, polyacrylamides are sensitive to saline solutions where in high salinity water, polymer molecules tend to curl up and lose their viscosity-building capability.

On the other hand, Xanthan polymers are more tolerant to mechanical shear and saline conditions, but they are very sensitive to biological degradation. Xanthan polymers are not retained on rock surfaces whereas polyacrylamides are subjected to retention, which causes reduction in rock permeability. Both polymers are unstable in high temperature conditions and oxidation by dissolved oxygen in the injected water (Green and Willhite 1998; Delamaide 2018). Promising biopolymers include Scleroglucan and Schizophyllan biopolymers, which have many similarities to Xanthan. $\mathrm{Pu}$ et al. (2017) reported different eco-friendly and tough biopolymers as opposed to synthetic polymers including Scleroglucan, HEC, CMC, Welan gum, Guar Gum, Schizophyllan, Mushroom polysaccharides Cellulose, and Lignin.

The main challenge with biopolymers is the poor filterability and plugging during flow in the porous media. This plugging problem is due to the presence of organic material or microgels (Carter et al. 1980). Kohler and Chauveteau (1981) stated that a potential polymer should be qualified through corefloods with low polymer retention ( $<84 \mu \mathrm{g} / \mathrm{g}$ of rock) and less pore volumes to achieve a steady state pressure drop (2-3 PVs).

\section{Biopolymer applications}

Several applications have been reported for biopolymers by which they improve volumetric sweep efficiency beyond conventional waterflooding. These applications include improving oil fractional flow, reduction mobility ratio, diverting water to unswept regions of the reservoir, and improving vertical sweep efficiency through conformance control (Needham and Doe 1987; Huh and Pope 2008; Qi et al. 2017; Erincik et al. 2018; Azad and Trivedi 2019).

\section{Biopolymer screening studies}

Several factors affect the performance of polymer flooding including characteristic of polymer solution itself, technical, economical, and reservoir conditions. Characteristics of polymer solution include but not limited to polymer molecular weight, polymer concentration, degree of hydrolysis, viscoelastic properties of the polymer solution, salinity, and $\mathrm{pH}$ of make-up water solution. Better sweep efficiency is usually achievable with a combination of low salinity, high molecular weight, and high concentration of polymers. Other technical, economical, and reservoir factors include injectivity problems, shear dependence behavior of polymers, polymer retention/adsorption, connate water salinity, $\mathrm{pH}$, rock wettability, reservoir temperature, oil viscosity, and amount of mobile oil saturation left after conventional waterflooding (Sorbie 1991; Green and Willhite 1998). Polymer retention affects the economics as well as the performance of polymer. Initial rock wettability state was found to affect polymer adsorption. Usually, in intermediate-wet reservoirs, significant portions of rock surface are occupied by crude oil components, which reduce the adsorption sites available for polymers. Hence, in water-wet reservoirs, polymer adsorption is more pronounced which results in a poor sweep efficiency (Chiappa et al. 1999). As most of carbonates are mixed-to-oil wet, then polymer adsorption is expected to be lower than that of sandstones.

\section{Biopolymer corefloods}

Polymer screening studies are followed by corefloods to qualify a polymer for EOR. The Polymer corefloods have been mainly conducted on sandstones with a limited application on carbonates where the promising results motivated researchers to perform further studies (Manrique et al. 2006). The corefloods conducted on carbonates are few with temperature up to $109^{\circ} \mathrm{C}$ and salinity of $343,000 \mathrm{ppm}$ using mainly synthetic polymers as opposed to biopolymers (Al-Hashim et al. 1996; Bennetzen et al. 2014; Han et al. 2014; and Zhu et al. 2015).

\section{Biopolymer numerical modeling}

After conducting both polymer screening studies and corefloods, the properties of these qualified polymers are needed as an input in a numerical simulator for history matching as well as upscaling of these corefloods to field-scale studies. The simulations are later used to optimize polymer flooding through running sensitivity studies on polymer concentration, injection rates, and other factors that affect the economics of this process (Lee 2015).

Bondor et al. (1972) introduced rheological behavior modeling of polymers with an emphasis on polymer injectivity and near wellbore effect. The authors included the nonideal mixing of polymer and water, polymer adsorption, and permeability reduction due to polymer adsorption in their simulator. Since that time, several numerical studies have been performed to highlight the effect of polymer flooding on enhancing oil recovery as well as optimizing this process. A summary of the basic functions in a polymer module was provided by Goudarzi et al. (2013), which include models for polymer viscosity as a function of both concentration and shear rate, polymer adsorption, permeability reduction, inaccessible pore volume, salinity, and hardness. One should 
note that very few numerical studies investigated the effect on polymer flooding in carbonates under harsh conditions.

Therefore, this work focuses on the numerical investigation of biopolymer injection in carbonate reservoirs under harsh conditions. The focus of this work is mainly on the core-scale simulations, which is considered the first step towards field-scale studies.

\section{Experimental data}

This work includes predictions of Schizophyllan biopolymer effect on oil recovery from carbonate cores. The study starts with history matching a waterflooding process on a Middle Eastern carbonate cores. The latter is followed by modeling the Schizophyllan biopolymer properties as reported from the screening studies by Quadri (2015). Afterwards, predictions of oil recovery by this biopolymer are performed in both secondary and tertiary modes of injection. The simulator used in this work is UTCHEM (Technical Documentation 2000), which is a 3D multiphase-flow, transport, and chemical-flooding simulator developed at the University of Texas at Austin.

Quadri (2015) presented a screening study for Schizophyllan biopolymer to be used in Middle Eastern carbonate reservoirs with high temperature and high salinity conditions. The latter polymer showed shear thinning behavior with excellent thermal stability (at $120^{\circ} \mathrm{C}$ ) and salt tolerance (up to 200,000 ppm). In addition, Schizophyllan showed good injectivity on cores with permeability higher than $30 \mathrm{mD}$. Dynamic adsorption was also discussed on cores of different permeabilities (3-163 $\mathrm{mD}$ ) and was found to be low within $7-48 \mu \mathrm{g} / \mathrm{g}$ of rock. Later, Li (2015) conducted several corefloods to highlight the injectivity of this Schizophyllan biopolymer. Moreover, a polymer concentration of $200 \mathrm{ppm}$ was used in these experiments. The current study utilizes polymer solution properties through the screening studies conducted by Quadri (2015) as well as rock and fluid properties through corefloods conducted by Li (2015). The latter data are used to numerically investigate the effect of this biopolymer with the proposed concentration (200 ppm) on enhancing oil recovery for the target reservoirs in the Middle East.

One of the corefloods conducted by $\mathrm{Li}$ (2015) was utilized to get rock and fluid data as well as relative permeability and capillary pressure curves for formation waterflooding through history matching using UTCHEM. In this coreflood, the core was flooded with formation water at reservoir conditions ( $248^{\circ} \mathrm{F}$ and $\left.3000 \mathrm{psig}\right)$. The core plug used has an average porosity of $13.12 \%$ and an average liquid permeability of $30.5 \mathrm{mD}$. More details about this coreflood including rock and fluid properties are listed in Tables 1 and 2. More information about the screening work of the Schizophyllan biopolymer used can be found elsewhere (Quadri 2015).
Table 1 Rock petrophysical properties

\begin{tabular}{lll}
\hline Pore Volume & 10.36 & $\mathrm{cc}$ \\
Porosity & 0.1312 & \\
Permeability & 30.5 & $\mathrm{mD}$ \\
Diameter & 3.80 & $\mathrm{~cm}$ \\
Cross Sectional Area & 11.341 & $\mathrm{~cm}^{2}$ \\
Length & 7.21 & $\mathrm{~cm}$ \\
Injection Rate $\left(\mathrm{cm}^{3} / \mathrm{min}\right)$ & 0.2 & \\
Capillary Number $\left(\mathrm{N}_{\mathrm{c}}\right)$ & $9.80 \times 10^{-7}$ & \\
$\mathrm{~S}_{\mathrm{wi}}$ & 0.304 & \\
$\mathrm{~S}_{\mathrm{oi}}$ & 0.696 & \\
$\mathrm{~S}_{\text {orw }}$ & 0.251 & \\
\hline
\end{tabular}

Table 2 Fluid properties

\begin{tabular}{ll}
\hline Oil Viscosity (cP) @ $248{ }^{\circ} \mathrm{F}$ & 0.815 \\
Oil Density (g/cc) @ $248^{\circ} \mathrm{F}$ & 0.755 \\
Oil API (Degrees) & 38.164 \\
Water Viscosity (cP) @ $248^{\circ} \mathrm{F}$ & 0.385 \\
Water Density (g/cc) @ $248^{\circ} \mathrm{F}$ & 1.063 \\
Water Salinity (ppm) & 168,949 \\
\hline
\end{tabular}

\section{Simulation model}

A 2D Cartesian grid was used with $10 \times 1 \times 10$ gridblocks to simulate the heterogeneous carbonate core plug for the coreflood. The simulation model was created horizontally to match the coreflood that was run in the lab. The heterogeneity was considered by generating permeability distribution with an arithmetic mean of $30.5 \mathrm{mD}$ and Dykstra Parson's coefficient $\left(\mathrm{V}_{\mathrm{DP}}\right)$ of 0.85 . The arithmetic mean value matches the core's average permeability. Also, the latter $\mathrm{V}_{\mathrm{DP}}$ was selected based on the experiences in dealing with carbonate cores from the same formation (Al-Shalabi 2014a, 2014b; Al-Shalabi et al. 2014a, 2014b). A spherical variogram and a lognormal permeability distribution were used. The spherical variogram was utilized which represents a medium level of heterogeneity between Gaussian and Exponential variograms. Equal correlation lengths in $\mathrm{x}$ - and $\mathrm{y}$-directions were used; however, a lower value was assigned in the $\mathrm{z}$-direction. This resulted in generating horizontal layers of different permeabilities as shown in Fig. 1. The latter horizontal layers aided in capturing the breakthrough of water observed during the experimental coreflood. It is worth mentioning that the number of gridblocks and the heterogeneity distribution used were chosen in a way to capture the physics and mimic the heterogeneity of the actual core where several grid sensitivities were performed. The simulation model has two vertical wells 
Fig. 1 Simulation model used in different runs with heterogeneous permeability

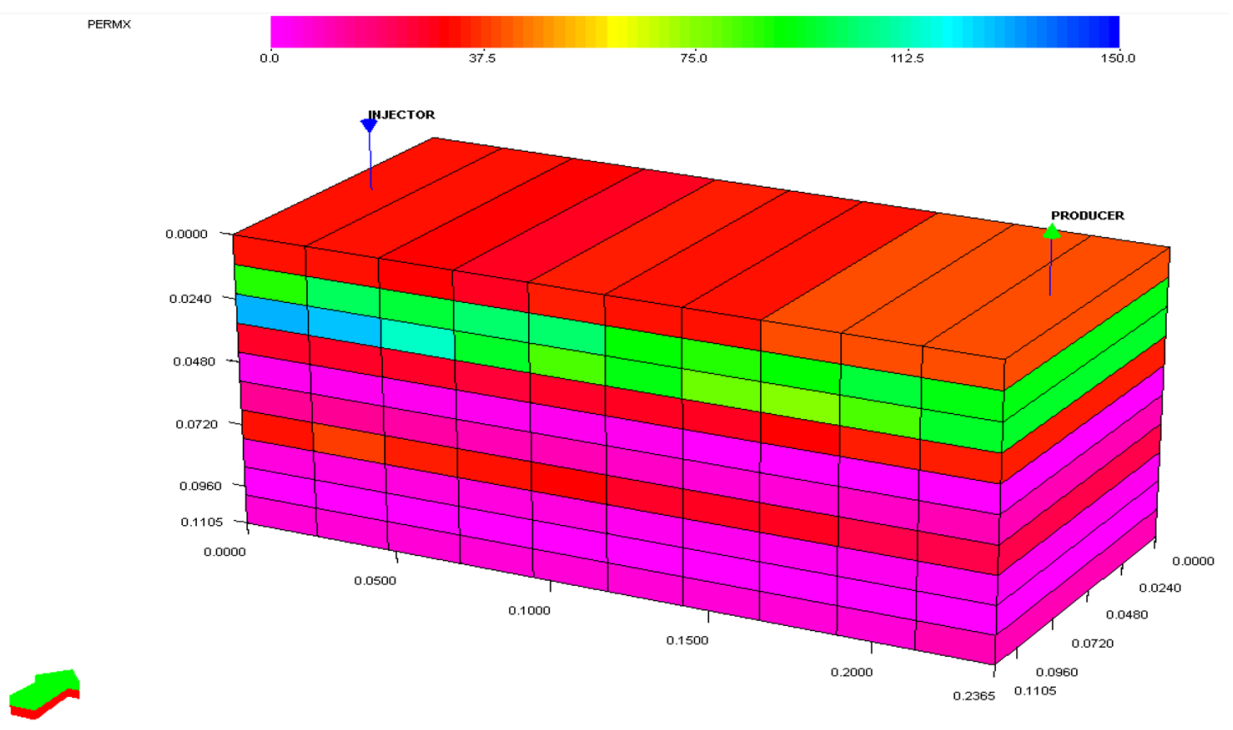

including an injector and a producer. More details about the simulation model are listed in Table 3.

The sections below discuss formation water cycle history matching, biopolymer properties modeling, analytical determination of optimum biopolymer concentration, both fractional flow and mobility ratio analyses, and numerical core-scale simulations.

\section{Results and discussion}

\section{Waterflooding history matching (secondary injection)}

The experimental data of the formation water coreflood, including pressure drop and oil recovery, were analyzed to find the relative permeability curves. Darcy's law and the stabilized pressure drop were used to determine the water endpoint relative permeability $\left(\mathrm{k}_{\mathrm{rw}}{ }^{*}\right)$ and the oil endpoint relative permeability $\left(\mathrm{k}_{\mathrm{ro}}{ }^{*}\right)$ was provided in the experimental work. The latter two parameters were used in Corey's correlation along with Corey's oil and water exponents $\left(\mathrm{n}_{\mathrm{o}}\right.$ and $n_{w}$ ) to estimate the relative permeability curves for the formation water injection cycle. Moreover, Brooks-Corey correlation for imbibition capillary pressure of mixed-wet rocks was used to estimate the capillary pressure curve for this injection cycle (Brooks and Corey 1966).

One should note that the final selection of Corey's exponents and capillary pressure parameters was based on the best history matching of both oil recovery and pressure drop experimental data for the formation water cycle. Endpoint relative permeability data analysis as well as a summary of relative permeability and capillary pressure parameters for the formation water injection cycle are listed in Tables 4 and 5, respectively.

Relative permeability and capillary pressure curves used in history matching are depicted in Figs. 2 and 3, respectively. Both relative permeability and capillary pressure curves are consistent as they show a mixed-to-weakly water wet carbonate rock.

The latter curves resulted in a good history match for both oil recovery and pressure drop data as shown in Figs. 4 and 5, respectively. As seen from these figures, both heterogeneity and capillary pressure effects were considered in the history matching process. It is worth to highlight that a reasonable history match was only obtained
Table 3 Heterogeneous core model data

\begin{tabular}{lll}
\hline Parameter & Value & Comments \\
\hline Number of Gridblocks & 100 & $2 \mathrm{D}(10 \times 1 \times 10)$ \\
Gridblock Sizes $(\Delta \mathrm{x}, \Delta \mathrm{y}, \Delta \mathrm{z}), \mathrm{m}$ & $\mathrm{X}$ direction: $1-10, \Delta \mathrm{x}$ & Constant grid size in the \\
& $0.00721 \mathrm{~m}$ & $\mathrm{x}, \mathrm{y}$ and $\mathrm{z}$ directions \\
& Y direction: $1-1, \Delta \mathrm{y}$ is & \\
& $0.033677 \mathrm{~m}$ & \\
Z direction: $1-10, \Delta \mathrm{z}$ is & \\
Core Model Dimensions, $\mathrm{m}$ & $0.0033677 \mathrm{~m}$ & \\
& $0.0721 \mathrm{~m} \times 0.033677 \mathrm{~m} \times 0.0$ & Length $\times$ Width $\times$ Height \\
& $33677 \mathrm{~m}$ & \\
\hline
\end{tabular}


Table 4 Endpoint relative permeability data analysis (formation water cycle)
Table 5 Summary of relative permeability and capillary pressure parameters (formation water cycle)

\begin{tabular}{|c|c|c|c|c|c|}
\hline Oil Viscosity & 0.815 & $\mathrm{cP}$ & Oil-Water IFT $(\sigma)$ & 30 & dynes/cm \\
\hline Composite Core Length & 7.21 & $\mathrm{~cm}$ & & & \\
\hline Cross Sectional Area & 11.341 & $\mathrm{~cm}^{2}$ & & & \\
\hline Injection Rate (Main) & 0.2 & $\mathrm{~cm}^{3} / \mathrm{min}$ & $\Delta \mathrm{P}_{\text {initial }}$ & 8 & psi \\
\hline Absolute Brine Permeability & 30.5 & $\mathrm{mD}$ & & & \\
\hline Injection Cycle & $\begin{array}{l}\text { Water } \\
\text { Viscosity } \\
\text { (cP) }\end{array}$ & Pressure Drop (psi) & $\mathrm{k}_{\mathrm{rw}}{ }^{*}$ & $\mathrm{~S}_{\text {orw }}$ & $\mathrm{k}_{\mathrm{ro}}{ }^{*}$ \\
\hline Formation Water Cycle & 0.385 & 6.20 & 0.063 & 0.251 & 0.104 \\
\hline
\end{tabular}

Formation water cycle match parameters

Relative permeability parameters

$\begin{array}{llll}\mathrm{k}_{\mathrm{rw}}{ }^{*} & 0.063 & \mathrm{n}_{\mathrm{w}} & 1.5 \\ \mathrm{k}_{\mathrm{ro}}{ }^{*} & 0.104 & \mathrm{n}_{\mathrm{o}} & 1.5\end{array}$

Capillary pressure parameters

$\begin{array}{llll}\mathrm{CPC}_{1} & 4 & \mathrm{EPC}_{1} & 2 \\ \mathrm{CPC}_{2} & -4 & \mathrm{EPC}_{2} & 2 \\ \mathrm{~S}^{*} & 0.6 & & \end{array}$

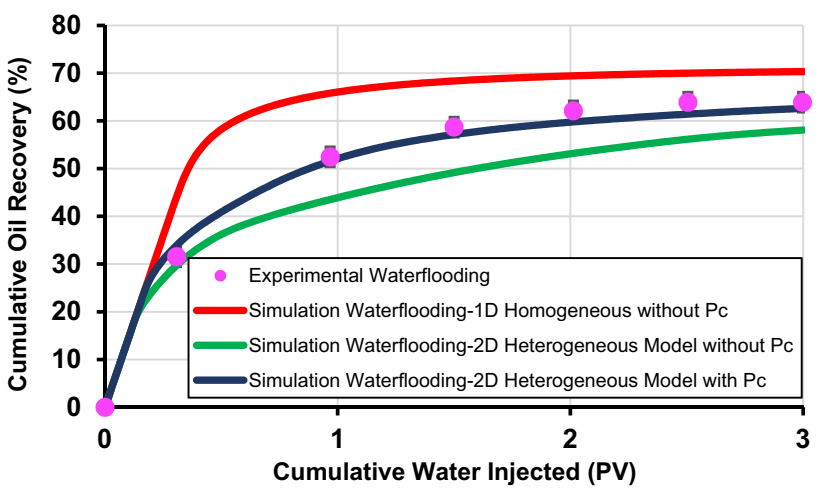

Fig. 4 Cumulative oil recovery match (formation water cycle)

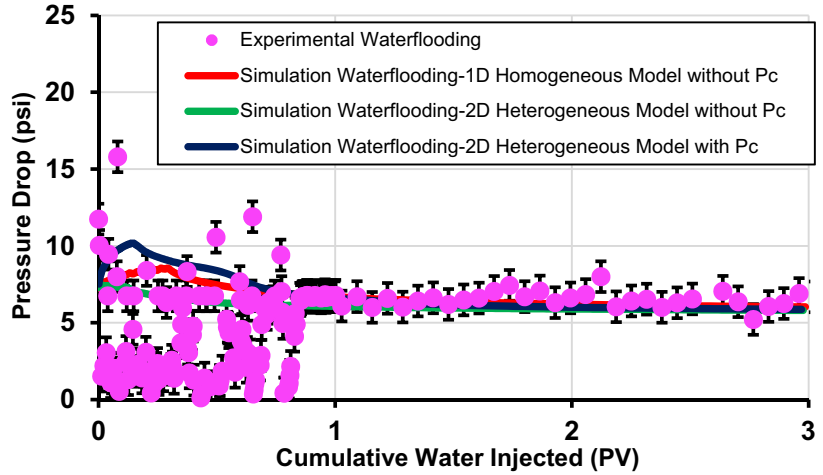

Fig. 5 Overall pressure drop match (formation water cycle)

after considering the contributions of both heterogeneity and capillary pressure.

\section{Biopolymer properties modeling}

In this section, modeling of the different properties of the Schizophyllan biopolymer is discussed. It is worth mentioning that the equations used below are usually applicable for both synthetic- and bio-polymers; however, the input parameters for these equations are different and usually they are obtained from the screening studies in the lab. In this work, the screening tests by Quadri (2015) were utilized.

Fig. 3 Capillary pressure curve (formation water cycle) 


\section{Polymer viscosity, salinity, and concentration}

Polymer viscosity is important in mobility control of the injected polymer solution. Polymer viscosity increases with increasing polymer concentration whereas it decreases with increasing the solution salinity. The dependence of polymer solution viscosity at zero shear rate $\left(\mu_{p}^{0}\right)$ on both polymer concentration and salinity are modeled using the Flory-Huggins equation (Flory 1953):

$\mu_{p}^{0}=\mu_{w}\left(1+\left(A_{p 1} C_{p}+A_{p 2} C_{p}^{2}+A_{p 3} C_{p}^{3}\right) C_{s e p}^{S_{p}}\right)$,

where $\mu_{w}$ is the water viscosity in $\mathrm{cP}, \mathrm{C}_{\mathrm{p}}$ is the polymer concentration in water, $\mathrm{A}_{\mathrm{p} 1}, \mathrm{~A}_{\mathrm{p} 2}, \mathrm{~A}_{\mathrm{p} 3}$, and $\mathrm{S}_{\mathrm{p}}$ are fitting constants, and $\mathrm{C}_{\text {sep }}$ is the effective polymer salinity. It should be noted that the units for the parameters inside the parentheses must be dimensionless so that the unit for $\mu_{p}^{0}$ be the same as $\mu_{w}$. $\mathrm{C}_{\text {sep }}$ captures the dependency of polymer viscosity on both salinity and hardness, and is defined as:

$C_{\text {sep }}=\frac{C_{51}+\left(\beta_{p}-1\right) C_{61}}{C_{11}}$,

where $\mathrm{C}_{51}$ and $\mathrm{C}_{61}$ are the anion and the divalent concentrations in the aqueous solution in $\mathrm{meq} / \mathrm{mL}$, respectively. $\mathrm{C}_{11}$ is the water concentrations in the aqueous phase and it is expressed as water volume fraction in the aqueous phase. $\beta_{\mathrm{p}}$ is measured in the laboratory, with typical value of about 10 . In $\mathrm{C}_{\text {sep }}$ calculation, usually the total amount of chloride ion is considered because $\mathrm{NaCl}$ is the most common salt in the water used and the current technology cannot describe the effect of every single ion on chemical EOR. Also, $\beta_{\mathrm{p}}$ was assumed to be equal to 1 , which means the hardness effect on polymer solution was ignored. Moreover, $\mathrm{C}_{11}$ was assumed to be 1 .

It is worth mentioning that $S_{p}$ is the slope of $\frac{\mu_{\mathrm{p}}^{0}-\mu_{\mathrm{w}}}{\mu_{\mathrm{w}}}$ versus $\mathrm{C}_{\text {sep }}$ on a $\log -\log$ plot (Fig. 6). Figure 7 shows the viscosity experimental data as well as data matching using Eq. (1). The results show that $A_{p 1}, A_{p 2}$, and $A_{p 3}$ are 2929, $44,528,44,528$, respectively, $\mathrm{C}_{\text {sep }}$ is $2.3 \mathrm{meq} / \mathrm{mL}, \mu_{w}$ is $1.25 \mathrm{cP}$, and $\mathrm{S}_{\mathrm{p}}$ is -0.33 .

\section{Shear effect}

Biopolymer solutions are pseudoplastic or shear thinning fluids, which means that their viscosity decreases with increasing the shear rate. The shear effect on polymer viscosity is modeled using Meter's equation (Meter and Bird 1964):

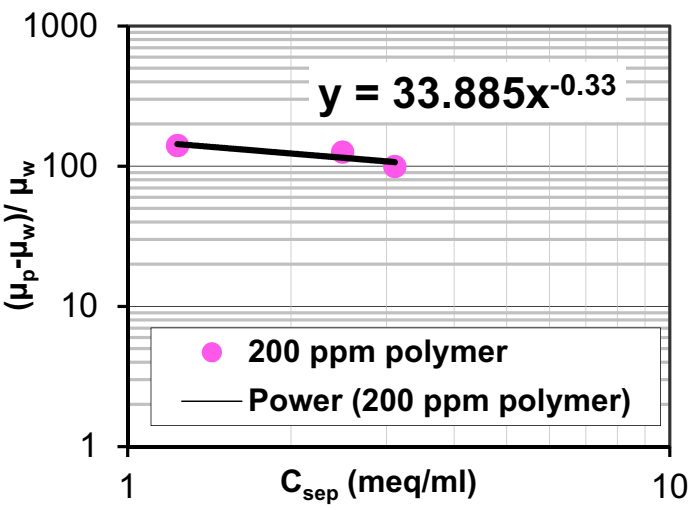

Fig. 6 Calcualtion of $S_{p}$

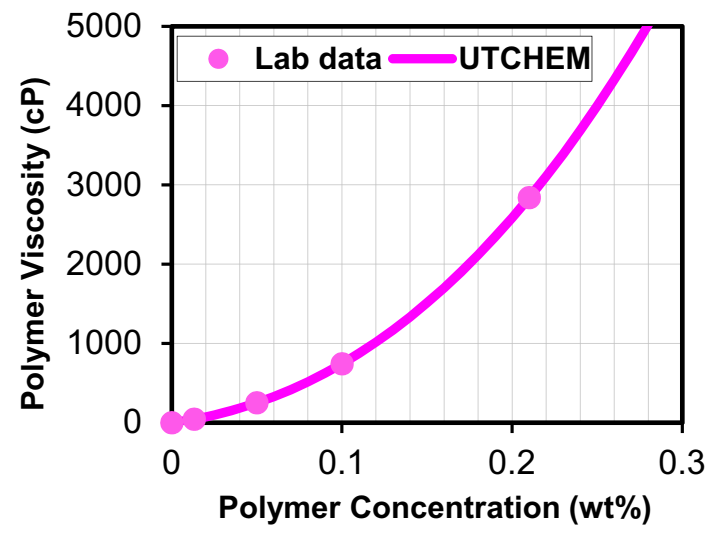

Fig. 7 Polymer viscosity versus polymer concentration at $25{ }^{\circ} \mathrm{C}$ and $10 \mathrm{~s}^{-1}$ shear rate

$\mu_{\mathrm{p}}=\mu_{\mathrm{w}}+\frac{\mu_{\mathrm{p}}^{0}-\mu_{\mathrm{w}}}{1+\left(\frac{\dot{\gamma}_{\mathrm{eq}}}{\dot{\gamma}_{1 / 2}}\right)^{\left(P_{\alpha}-1\right)}}$,

where $\mathrm{P}_{\alpha}$ is an empirical parameter that is obtained by matching laboratory-measured viscosity data, $\mu_{\mathrm{p}}^{0}$ is the limiting viscosity at low shear limit (approaching zero), $\mu_{\mathrm{w}}$ is the water viscosity which is the limiting viscosity at high shear limit (approaching infinity), and $\dot{\gamma}_{1 / 2}$ is the shear rate at which polymer viscosity is the average of the $\mu_{p}^{0}$ and $\mu_{w}$. The equivalent shear rate $\left(\dot{\gamma}_{e q}\right)$ is defined using Cannella equation (Cannella et al. 1988):

$\dot{\gamma}_{e q}=\frac{\dot{\gamma}_{c}\left|u_{l}\right|}{\sqrt{\bar{k} k_{r l} \emptyset S_{l}}}$,

$\dot{\gamma}_{c}=3.97 C$, 


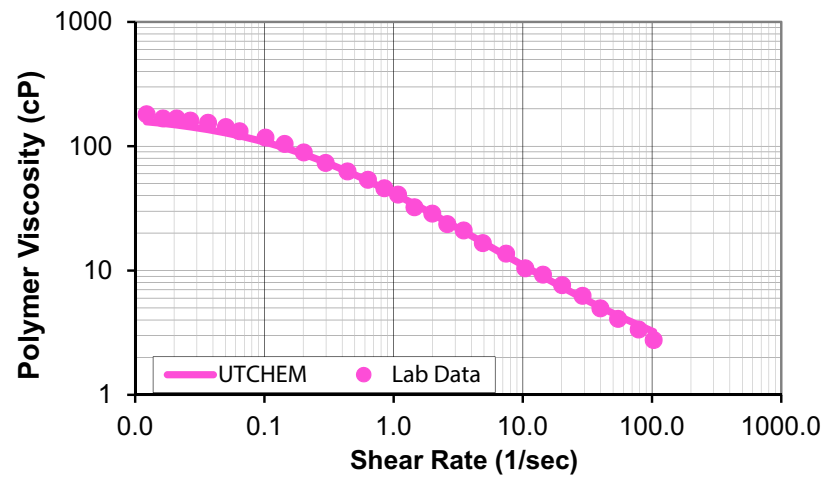

Fig. 8 Shear effect on polymer viscosity at $25^{\circ} \mathrm{C}$

where $\mathrm{u}$ is Darcy's velocity in $\mathrm{ft} / \mathrm{day}, \bar{k}$ is the formation average permeability in Darcy, and C is the shear rate coefficient that depends on permeability and porosity. In this work, $\mathrm{C}$ was assumed as 2.55 as the reported $\mathrm{C}$ value for Scleroglucan is around 2 to 3.1 (Kulawardana et al. 2012). Figure 8 depicts the shear rate effect on polymer viscosity where the results show that $\mathrm{P}_{\alpha}$ is $1.7, \dot{\gamma}_{c}$ is 10.12 , and $\dot{\gamma}_{1 / 2}$ is 0.173 .

One should note that polymer concentration and shear rate effects on Schizophyllan biopolymer viscosity are presented at $25{ }^{\circ} \mathrm{C}$ in Figs. 7 and 8, respectively. This is because Quadri (2015) observed a negligible effect of temperature on this biopolymer through his temperature sweep tests.

\section{Polymer adsorption}

Polymer retention could be either dynamic (mechanical trapping and hydrodynamic trapping) or static (adsorption). Mechanical trapping occurs due to the use of polymers with sizes greater than the pores of the porous medium and it happens during polymer flow. The latter could be controlled by using polymers in high permeability medium or pre-shearing of polymer solution. Hydrodynamic trapping occurs also during polymer flow in the medium where the polymer retention depends on the flow rate. Usually, this effect is negligible especially at field-applications. Adsorption is the most important mechanism, which occurs due to the interaction between polymer molecules and the solid rock surface. Adsorption depends on the surface area exposed to the polymer solution. Researchers usually use the term polymer retention to describe polymer loss or they simply use the term adsorption (Sheng 2011).

The Langmuir isotherm was used to describe adsorption (Lakatos et al. 1979):
$\hat{C}_{p}=\min \left(C_{p}, \frac{a_{p}\left(C_{p}-\hat{C}_{p}\right)}{1+b_{p}\left(C_{p}-\hat{C}_{p}\right)}\right)$,

where $\mathrm{C}_{\mathrm{p}}$ is the injected polymer concentration, $\widehat{C}_{p}$ is the adsorbed polymer concentration, $C_{p}-\hat{C}_{p}$ is the equilibrium concentration in the rock-polymer solution system, $a_{p}$ and $b_{p}$ are empirical constants. It should be noted that both $\mathrm{C}_{\mathrm{p}}$ and $\bar{C}_{p}$ have the same units, and $\mathrm{b}_{\mathrm{p}}$ has the reciprocal unit of $\mathrm{C}_{\mathrm{p}}$. Also, $\mathrm{a}_{\mathrm{p}}$ is dimensionless and defined as:

$a_{\mathrm{p}}=\left(a_{\mathrm{p} 1}-a_{\mathrm{p} 2} C_{\mathrm{sep}}\right)\left(\frac{k_{\mathrm{ref}}}{k}\right)^{0.5}$

where $\mathrm{a}_{\mathrm{p} 1}$ and $\mathrm{a}_{\mathrm{p} 2}$ are fitting parameters, $C_{\mathrm{sep}}$ is the effective salinity, $\mathrm{k}$ is the formation permeability, and $k_{\text {ref }}$ is the reference permeability of the rock used in the laboratory measurement for adsorption. It must be noted that Langmuir model assumes equilibrium conditions, instantaneous polymer adsorption as well as reversible adsorption in terms of polymer concentration. Polymer adsorption depends on polymer type, salinity, and rock surface. Figure 9 shows polymer adsorption modeling using the simulator where $\mathrm{a}_{\mathrm{p} 1}, \mathrm{a}_{\mathrm{p} 2}$, and $\mathrm{b}_{\mathrm{p}}$ obtained through data matching are $1.857,0$, and 100 , respectively. The experimentally reported adsorption is $6.9 \mu \mathrm{g} / \mathrm{g}$ of rock using a $200 \mathrm{ppm}$ polymer concentration and a $30.5 \mathrm{mD}$ reference core permeability.

\section{Permeability reduction}

There is a noticeable formation permeability change during polymer flooding compared to waterflooding. This permeability reduction is due to polymer adsorption. The permeability reduction factor $\left(\mathrm{F}_{\mathrm{kr}}\right)$ is defined as:

$F_{k r}=\frac{k_{e f f, w}}{k_{e f f, p}}$,

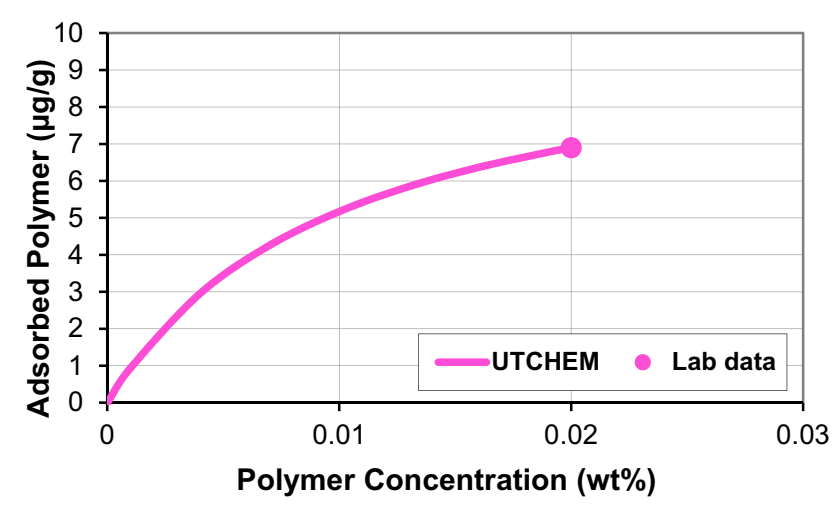

Fig. 9 Polymer adsorption modeling using UTCHEM at $120^{\circ} \mathrm{C}$

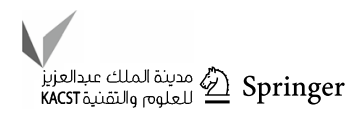


where $\mathrm{k}_{\text {eff, }}$ is the effective permeability when rock is flooded by water and $\mathrm{k}_{\text {eff, }}$ is the effective permeability when the rock is flooded with polymer solution. This factor is modeled using the following equations:

$F_{\mathrm{kr}}=1+\left(F_{\mathrm{kr}, \text { max }}-1\right)\left(\frac{b_{\mathrm{kr}} C_{\mathrm{p}}}{1+b_{\mathrm{kr}} C_{\mathrm{p}}}\right)$

$F_{\mathrm{kr}, \text { max }}=\min \left\{\left(1-\frac{c_{\mathrm{kr}}\left(A_{\mathrm{p} 1} C_{\mathrm{sep}}^{\mathrm{S}_{\mathrm{p}}}\right)^{1 / 3}}{\sqrt{\frac{k}{\emptyset}}}\right)^{-4}, 10\right\}$

where $b_{\mathrm{kr}}$ and $\mathrm{c}_{\mathrm{kr}}$ are input parameters derived from data matching, $A_{p 1}$ is the constant in Eq. (1), $C_{\text {sep }}$ is calculated using Eq. (2), and $S_{p}$ is from Fig. 6. It should be noted that the term $b_{k r} C_{p}$ must be dimensionless, similarly is the case for $\mathrm{F}_{\mathrm{kr} \text {,max }}$, which has an assumed empirical value of 10. Permeability reduction was modeled as seen in Fig. 10 through data matching using $\mathrm{b}_{\mathrm{kr}}$, and $\mathrm{c}_{\mathrm{kr}}$ values of 1000 and 0.00883 , respectively.

As the polymer adsorption process can be considered sometimes irreversible due to the prolonged pore volumes of water injection to restore the initial permeability, the residual resistance factor $\left(\mathrm{F}_{\mathrm{rr}}\right)$ was introduced. The latter parameter is defined as the ratio of water mobility before polymer flow to water mobility after polymer flow. However, $\mathrm{F}_{\mathrm{rr}}$ does not take into account the increase in viscosity caused by polymer flooding. Hence, the resistance factor term $\left(\mathrm{F}_{\mathrm{r}}\right)$ was introduced, which is defined as the ratio of water mobility during water flow to polymer mobility during polymer flow. It should be noted that viscosity increase and permeability reduction due to polymer flooding is only applicable to the water phase by modifying the polymer viscosity by $\mathrm{F}_{\mathrm{kr}}$.

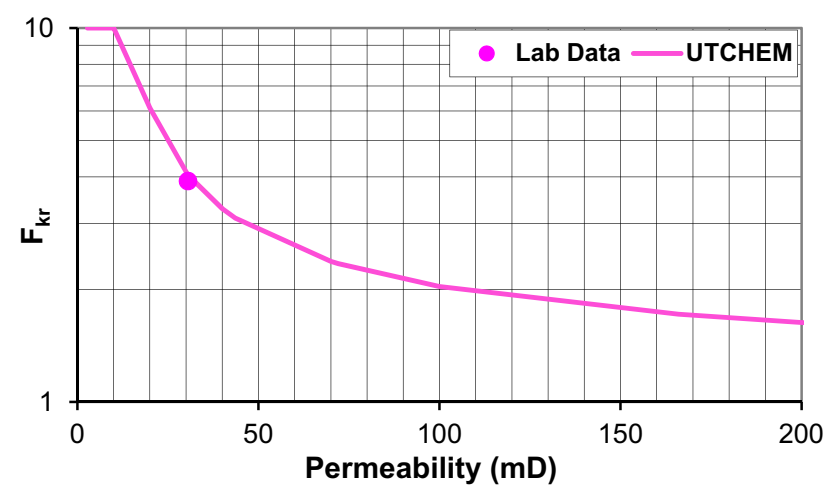

Fig. 10 Permeability reduction modeling using UTCHEM at $120{ }^{\circ} \mathrm{C}$

\section{Inaccessible pore volume (IPV)}

It refers to the fraction of pore volume where the radii of the pores are smaller than the size of polymer particles, especially when polymers with high molecular weight are used. These pores are usually filled with irreducible water. IPV has a positive effect on sweep efficiency of polymer solutions and hence, better oil recovery due to boosting the advancement of the polymer solution front. Moreover, the IPV is useful from an economical point of view where it results in less contact between rock surface and polymer solution and hence, less polymer adsorption/retention. The only disadvantage of IPV is when these inaccessible pores have movable oil droplets. In this situation, polymer solutions will not be able to contact these oil droplets and that oil remains as residual oil saturation (Dawson and Lantz 1971). IPV is modeled by multiplying the porosity in the conservation equation for polymer by an input parameter (EPHI4) defined as the effective porosity. EPHI4 is 1- IPV and assumed to be 1.0 in this study.

A summary of the parameters used in modeling the properties of the Schizophyllan biopolymer using the UTCHEM simulator is listed in Table 6. More details about modeling of polymer properties can be found elsewhere (Sheng 2011).

\section{Optimum biopolymer concentration analysis}

The optimum concentration of the Schizophyllan biopolymer was determined using an analytical method, which is based on achieving the minimum total relative mobility of

Table 6 A summary of the parameters used in modeling the properties of the Schizophyllan biopolymer using the UTCHEM simulator

\begin{tabular}{lll}
\hline Variable & UTCHEM parameter & Value \\
\hline Viscosity & $\mathrm{A}_{\mathrm{P} 1}$ & 2929 \\
& $\mathrm{~A}_{\mathrm{P} 2}$ & 44,528 \\
& $\mathrm{~A}_{\mathrm{P} 3}$ & 44,528 \\
& $\mathrm{~S}_{\mathrm{p}}$ & -0.33 \\
& $\beta_{\mathrm{p}}$ & 1 \\
& $\mathrm{C}_{\mathrm{sep}}(\mathrm{meq} / \mathrm{mL})$ & 2.3 \\
& $\mathrm{P}_{\alpha}$ & 1.7 \\
Shear effect & $\dot{\gamma}_{\mathrm{c}}$ & 10.12 \\
& $\dot{\gamma}_{1 / 2}$ & 0.173 \\
& $\mathrm{a}_{\mathrm{p} 1}$ & 1.857 \\
Adsorption & $\mathrm{a}_{\mathrm{p} 2}$ & 0 \\
& $\mathrm{~b}_{\mathrm{p}}$ & 100 \\
& $\mathrm{~b}_{\mathrm{kr}}$ & 1000 \\
Permeability reduction & $\mathrm{c}_{\mathrm{kr}}$ & 0.00883 \\
& $\mathrm{Effective} \mathrm{porosity} \mathrm{(EPHI4)} 1.0$ \\
Inaccessible pore volume & & \\
(IPV) & & \\
\hline
\end{tabular}




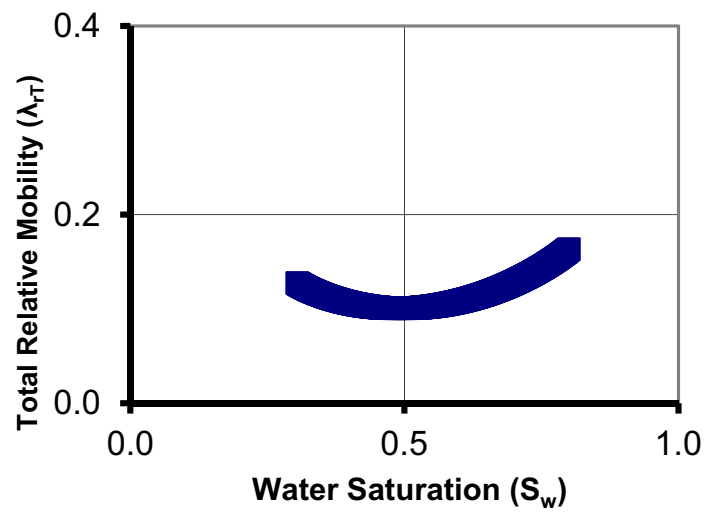

Fig. 11 Totall relative mobility of water and oil phaes during formation water injection

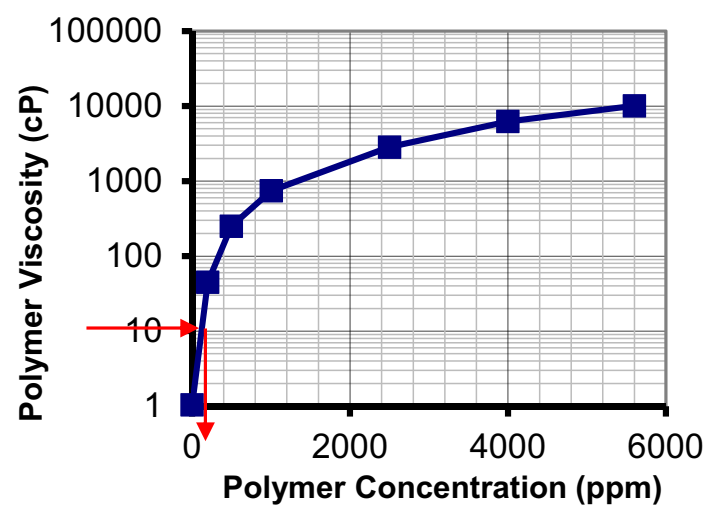

Fig. 12 Optimum polymer concnetration design at $120{ }^{\circ} \mathrm{C}$ and $10 \mathrm{~s}^{-1}$ shear rate

oil and water phases during the formation water injection cycle. The total relative mobility $\left(\lambda_{\mathrm{rT}}\right)$ is defined as:

$\lambda_{\mathrm{rt}}=\lambda_{\mathrm{rw}}+\lambda_{\mathrm{ro}}=\frac{k_{\mathrm{rw}}}{\mu_{\mathrm{w}}}+\frac{k_{\mathrm{ro}}}{\mu_{o}}$

where $\lambda_{\mathrm{rw}}$ and $\lambda_{\mathrm{ro}}$ are the relative mobility of water and oil phases, respectively. Figure 11 shows the calculated total relative mobility for water and oil phases where the minimum mobility was determined. Afterwards, the designed polymer viscosity is the inverse of this minimum total relative mobility as follows:

$\mu_{\mathrm{p}}=\frac{1}{\lambda_{\mathrm{rT}, \min }}$.

The obtained desired polymer viscosity of $10 \mathrm{cP}$ was used in Fig. 12 to determine the required optimum polymer concentration. The analysis shows that the optimum polymer concentration is $200 \mathrm{ppm}$, which results in a polymer viscosity of $10 \mathrm{cP}$. The latter is consistent with the polymer concentration used in $\mathrm{Li}$ (2015) studies.

\section{Fractional flow and mobility ratio analyses}

In this subsection, both fractional flow and mobility ratio analyses for biopolymer flooding are discussed.

\section{Fractional flow analysis}

Several assumption were considered in the fractional flow analysis including no dispersion, uniform adsorption of polymer on rock, one-dimensional linear flow, continuous injection of polymer, no chemical reactions, polymer only in aqueous phase (does not partition to oil), polymer viscosity depends on polymer concentration, isothermal reservoir, and local equilibrium adsorption of polymer on rock.

Two fractional flow curves were considered. First, the water-oil fractional flow equation for horizontal flow and neglecting capillary pressure effect:

$f_{\mathrm{w}}=\frac{1}{1+\frac{k_{\mathrm{r}} \mu_{\mathrm{w}}}{k_{\mathrm{rw}} \mu_{\mathrm{o}}}}$.

Second, the polymer-oil fractional flow equation for horizontal flow and neglecting capillary pressure effect:

$f_{\mathrm{p}}=\frac{1}{1+\frac{F_{\mathrm{kr}} k_{\mathrm{ro}} \mu_{\mathrm{p}}}{k_{\mathrm{rw}} \mu_{\mathrm{o}}}}$.

It is worth mentioning that the fractional flow analysis was conducted for the secondary mode of injection. The frontal advance loss $\left(\mathrm{D}_{\mathrm{p}}\right)$ in cc polymer/cc pore volume was calculated using the following equation:

$D_{p}=\frac{w_{p s} \rho_{s}(1-\emptyset)}{\emptyset C_{p}}$,

where $\mathrm{w}_{\mathrm{ps}}$ is the mass concentration of adsorbed polymer and $\rho_{\mathrm{s}}$ is the rock density $(2.71 \mathrm{~g} / \mathrm{cc})$. Afterwards, the intercept of the water saturation axis $\left(\phi_{\mathrm{e}}-D_{\mathrm{p}}\right)$ was found and a tangent was drawn to polymer fractional flow curve resulting in $\left(\mathrm{S}_{\mathrm{w}}{ }^{*}, \mathrm{f}_{\mathrm{p}}{ }^{*}\right)$ values and the intersection of this tangent with the water-oil fractional flow curve, results in the water shock (oil bank) saturation and fractional flow values $\left(\mathrm{S}_{\mathrm{wB}}, \mathrm{f}_{\mathrm{wB}}\right)$. The parameter $\phi_{\mathrm{e}}$ is defined as follows:

$\emptyset_{e}=\frac{\emptyset_{\mathrm{IPV}}}{\emptyset}$

It should be noted that $\phi_{\mathrm{e}}$ is zero in this study as IPV is zero. Water saturation at breakthrough and the corresponding water fractional flow value were considered in the analysis $\left(\mathrm{S}_{\mathrm{wbt}}, \mathrm{f}_{\mathrm{wbt}}\right)$. The fractional flow analysis is shown in Fig. 13 
where a more favorable fractional flow curve was obtained using polymer flooding as opposed to conventional formation water flooding.

This finding is consistent with Fig. 14a-d showing water cut, oil cut, dimensionless cumulative oil recovery, and saturation profile at $0.2 \mathrm{PV}$ using fractional flow calculations. The positive response of polymer flooding is clearly seen in the latter figures where a piston like displacement front was obtained using polymer flooding to the extreme of having one shock instead of the conventional two shocks solution. It should be noted that this solution was obtained under the assumptions made in this study.

\section{Mobility ratio analysis}

This analysis is essential in designing a polymer flooding process for a certain field. One should make sure that the mobility ratio is less than 1 for achieving a good mobility control by polymer and avoiding water fingering through the oil as well as early water breakthrough. In this work, the endpoint mobility ratio was calculated before and after polymer flooding using Eqs. (17) and (18), respectively.

$$
\begin{aligned}
& M_{\mathrm{w} / \mathrm{o}}^{*}=\frac{k_{\mathrm{rw}}^{*}}{k_{\mathrm{ro}}^{*}} \frac{\mu_{\mathrm{o}}}{\mu_{\mathrm{w}}}, \\
& M_{\mathrm{p} / \mathrm{o}}^{*}=\frac{k_{\mathrm{rw}}^{*}}{F_{\mathrm{kr}} k_{\mathrm{ro}}^{*}} \frac{\mu_{\mathrm{o}}}{\mu_{\mathrm{p}}} .
\end{aligned}
$$

The results show that the endpoint mobility ratio during formation waterflooding $\left(M_{\mathrm{w} / \mathrm{o}}^{*}\right)$ is 1.29 whereas the endpoint mobility rate during polymer flooding $\left(M_{\mathrm{p} / \mathrm{o}}^{*}\right)$ is 0.013 . The latter results indicate a slightly favorable endpoint mobility ratio during the formation waterflooding; however, this mobility ratio was further improved using the Schizophyllan biopolymer. This finding further indicates the capability of this biopolymer on improving volumetric sweep efficiency in carbonate reservoirs with harsh conditions of high temperature, high salinity, and low permeability.

Fractional flow and mobility ratio analyses give an indication about the performance of the polymer flooding technique; however, capillary pressure and heterogeneity effects are not captured. Therefore, the next subsections discuss the predictions of polymer flooding in secondary and tertiary modes of injection using the UTCHEM simulator with comparison between these two injection modes.

\section{Biopolymer flooding prediction (secondary injection)}

The prediction of biopolymer injection in the secondary mode of injection was investigated. Figure 15 shows cumulative oil recovery prediction, and Fig. 16 depicts total pressure drop prediction.

The figures show two polymer concentrations include 200 and $800 \mathrm{ppm}$. The reason behind using an $800 \mathrm{ppm}$ polymer concentration is the small-scale heterogeneity of the core model, which resulted in higher effective shearing effects and hence, lowers polymer viscosity than the desired
Fig. 13 Fractional flow curves of waterflood and polymer flood in the secondary mode of injection

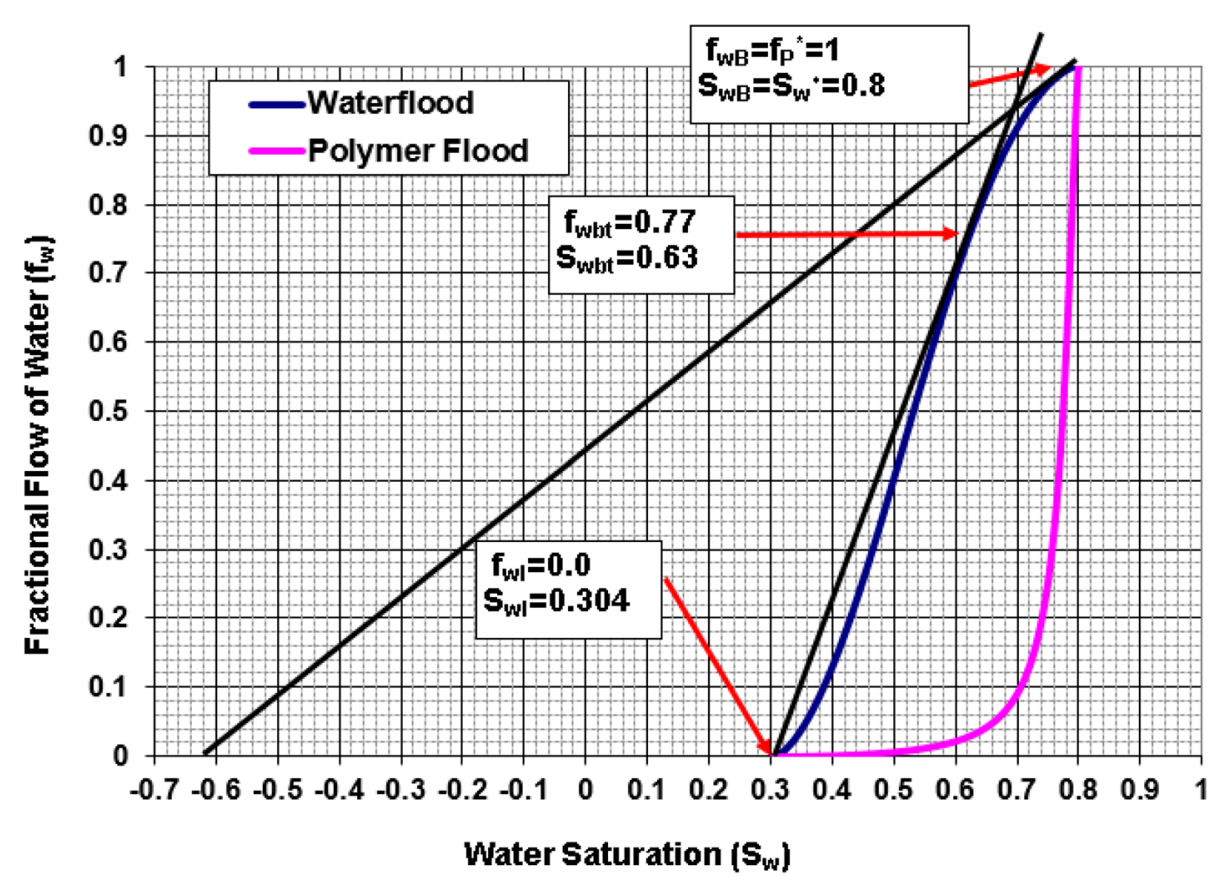




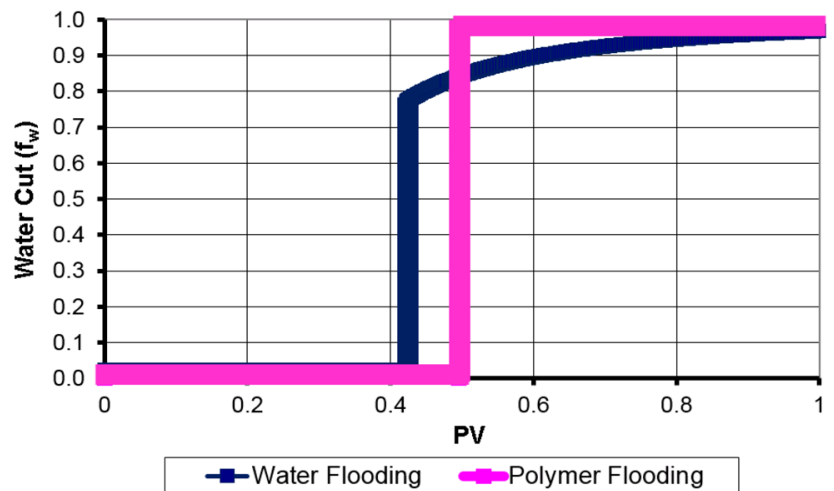

a Water cut $\left(\mathrm{f}_{\mathrm{w}}\right)$.

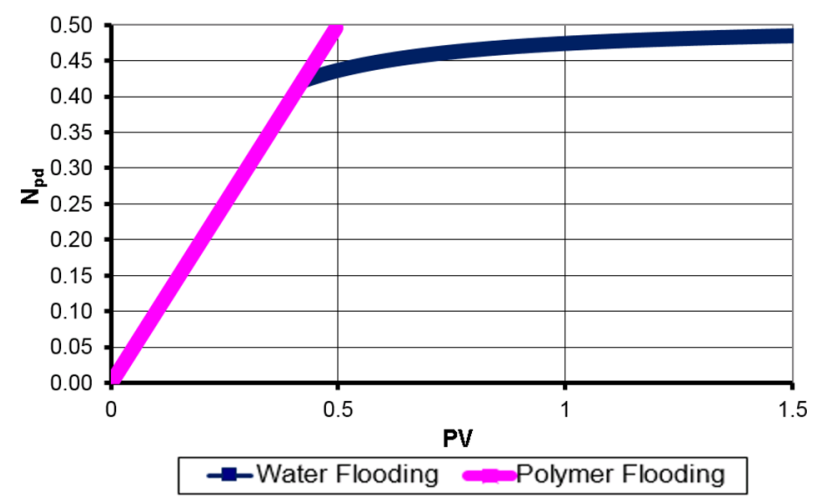

c Dimensionless cumulative oil recovery $\left(\mathrm{N}_{\mathrm{pd}}\right)$.

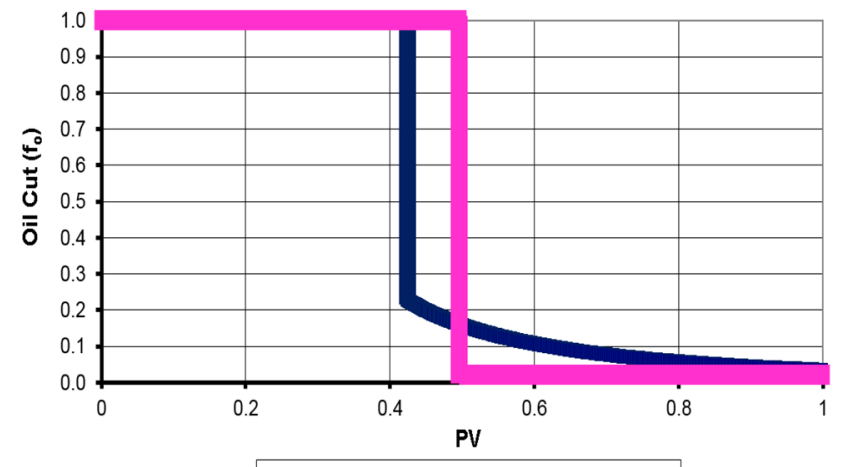

$\rightarrow$ Water Flooding $\quad$-Polymer Flooding

b Oil cut $\left(f_{0}\right)$.

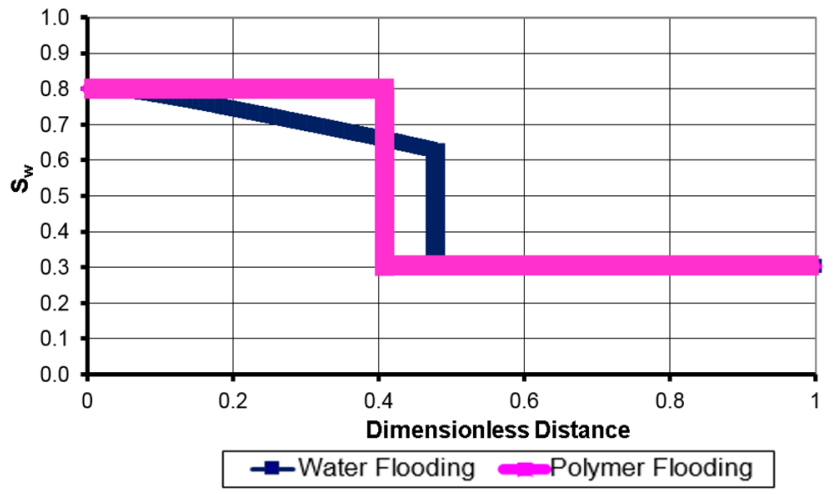

d Water saturation profile at $0.2 \mathrm{PV}$.

Fig. 14 Fractional flow calculations of water and polymer floods in the secondary injection

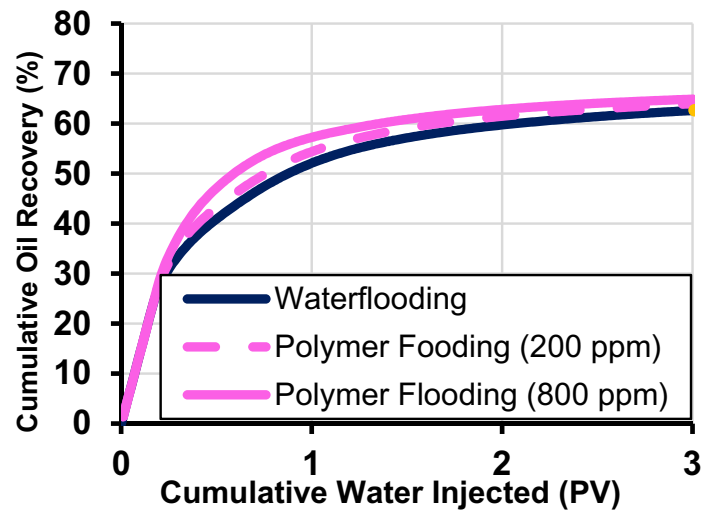

Fig. 15 Cumulative oil recovery (polymer flooding-secondary injection mode)

polymer viscosity $(10 \mathrm{cP})$. Figure 17 shows the polymer viscosity corresponding to polymer concentration of $200 \mathrm{ppm}$ whereas Fig. 18 shows that the use of 800 ppm polymer

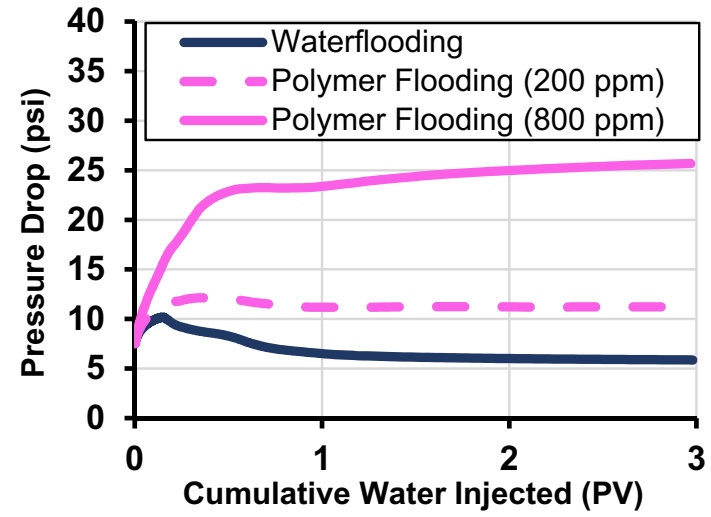

Fig. 16 Total pressure drop (polymer flooding-secondary injection mode)

concentration achieves the desired polymer viscosity of 10 cP. In these two figures, there are zones with high viscosity, which is related to their corresponding high permeability. 
Fig. 17 Polymer viscoisty at 200 ppm polymer concentration (polymer flooding-secondary injection mode)
Fig. 18 Polymer viscoisty at 800 ppm polymer concentration (polymer flooding-secondary injection mode)

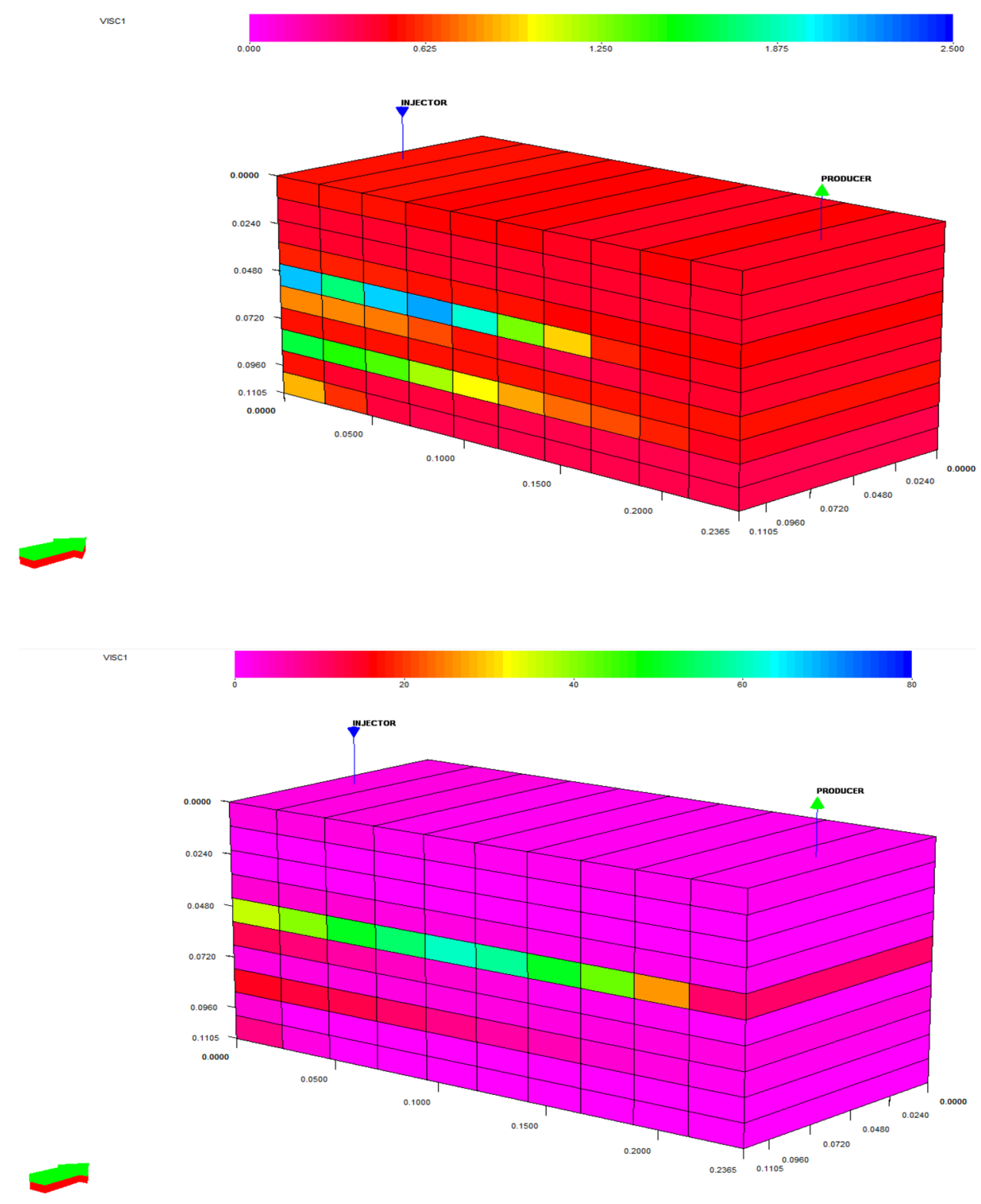

This can be crosschecked with the permeability model, which was previously shown in Fig. 1. Zones with high permeability experience low effective shear rate, and consequently, high polymer viscosity, which is consistent with Eqs. (3) and (4).

The higher polymer viscosity results in better sweep efficiency as shown in the 3D saturation maps in Figs. 19 and 20.

Figure 19 shows the water saturation in the core model as a result of formation water flooding at 3 pore volumes of water injection where it is clear that zones with high permeability have better sweep compared to others. On the other hand, Fig. 20 shows the improvement in sweep efficiency as a result of polymer injection in the secondary mode at 3 pore volumes of injection. The improvement is related to the decrease in water mobility by decreasing effective water permeability and increasing water viscosity by using the Schizophyllan biopolymer at concentration of $800 \mathrm{ppm}$. The results of secondary biopolymer injection are also listed in Table 7.

Both Fig. 15 and Table 7 show that polymer flooding with $800 \mathrm{ppm}$ concentration results in better oil recovery compared to the $200 \mathrm{ppm}$ polymer concentration. Moreover, biopolymer flooding is more favorable as opposed to conventional formation waterflooding resulting in incremental oil recovery of about 1.36 and $2.26 \%$ OOIP for 200 and 800 ppm polymer concentrations, respectively. In addition, it is worth mentioning that the injectivity of polymer is lower than that of waterflood due to the increase of pressure drop, which is about 2-5 times higher than that 
Fig. 19 Water saturation map at $3 \mathrm{PV}$ of formation water injection (formation waterfloodingsecondary injection mode)

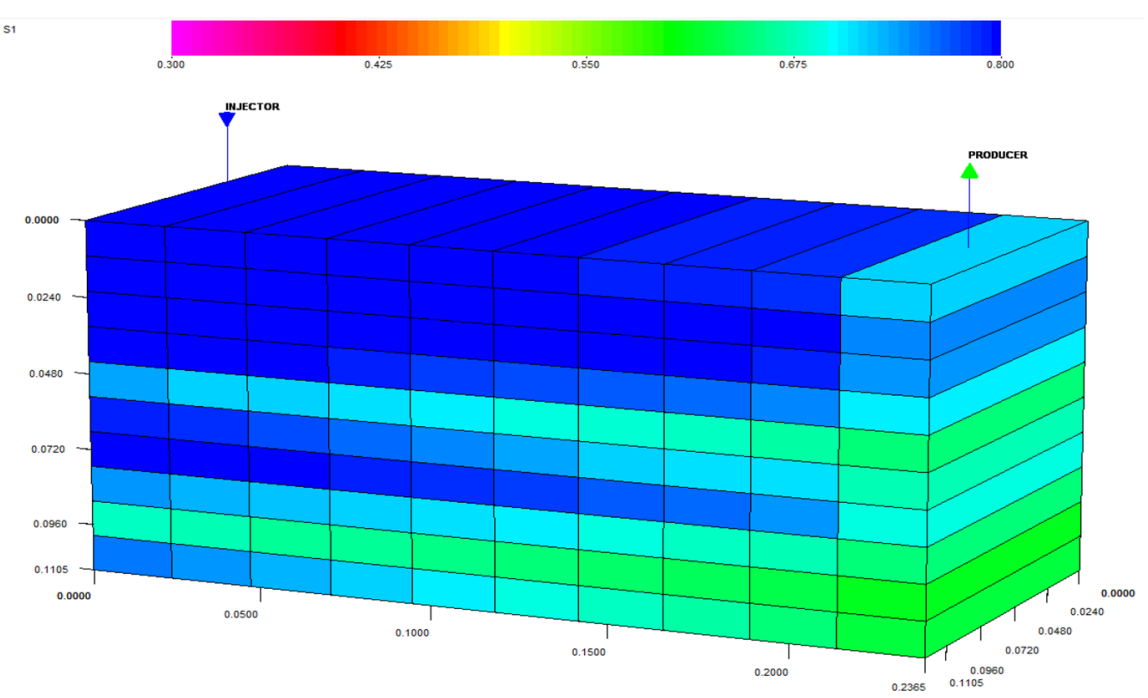

Fig. 20 Water saturation map at $3 \mathrm{PV}$ of polymer injection using $800 \mathrm{ppm}$ polymer concentration (polymer flooding-secondary injection mode)
Table 7 Prediction of secondary polymer flooding using the UTCHEM simulator

\begin{tabular}{lcl}
\hline Secondary polymer flooding (3 PVs of Injection) & \\
\hline Injection technique & Oil recovery (\%) & $\begin{array}{l}\text { Incremental } \\
\text { oil recovery } \\
(\%)\end{array}$ \\
\hline Formation waterflooding & 62.63 & - \\
Polymer flooding (200 ppm) & 63.99 & 1.36 \\
Polymer flooding (800 ppm) & 64.89 & 2.26 \\
\hline
\end{tabular}

of the waterflood when using 200 and 800 ppm polymer concentrations, respectively (Fig. 16). It is worth mentioning that permeability, viscosity, and saturation maps are consistent in justifying the incremental oil recovery achieved by polymer flooding.

\section{Biopolymer flooding prediction (tertiary injection)}

The injection of the Schizophyllan biopolymer was also investigated in the tertiary mode of injection using UTCHEM. This mode starts with injecting formation water for about 3 pore volumes followed by polymer injection for another 3 pore volumes, which makes the total injection of 6 pore volumes. Figures 21 and 22 depict the cumulative oil recovery and the total pressure drop predictions as a result of tertiary polymer flooding.

The stabilized pressure drop during the polymer flooding indicates that there is no injectivity or plugging problems. However, it is also evident from Fig. 22 that the injectivity of polymer is lower than that of waterflood due to the increase of pressure drop, which is about 2 to 5 times higher than that of the waterflood when using $200 \mathrm{ppm}$ and $800 \mathrm{ppm}$ polymer concentrations, respectively. The findings are consistent with 


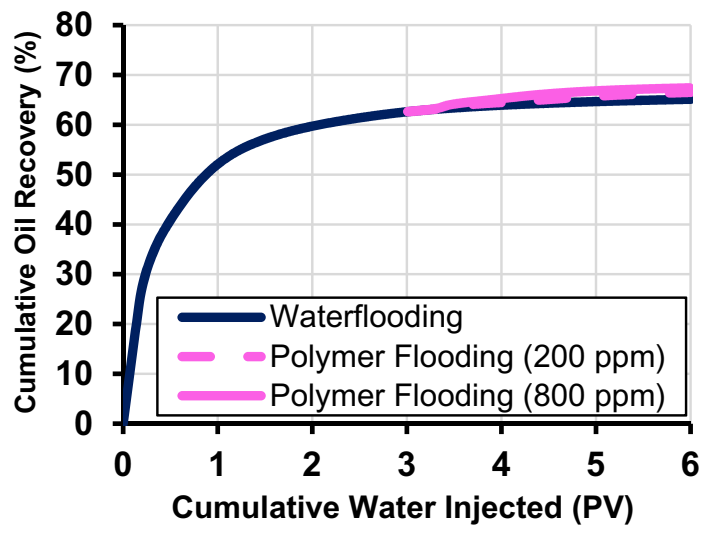

Fig. 21 Cumulative oil recovery (polymer flooding-teritary injection mode)

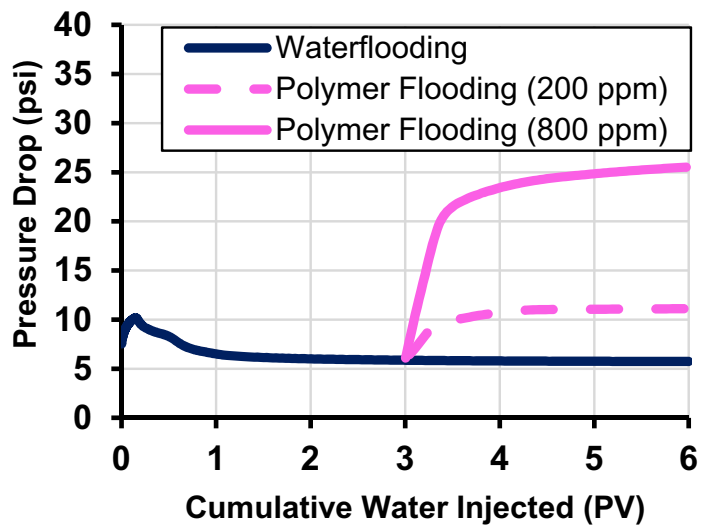

Fig. 22 Total pressure drop (polymer flooding-tertiary injection mode)

Table 8 Prediction of tertiary polymer flooding using the UTCHEM simulator

\begin{tabular}{lcl}
\hline Tertiary Polymer Flooding (6 PVs of Injection) & \\
\hline Injection technique & Oil recovery (\%) & $\begin{array}{l}\text { Incremental } \\
\text { oil recovery } \\
(\%)\end{array}$ \\
\hline Formation water flooding & 65.14 & - \\
Polymer flooding (200 ppm) & 66.52 & 1.38 \\
Polymer flooding (800 ppm) & 67.42 & 2.29 \\
\hline
\end{tabular}

the secondary mode of injection where the $800 \mathrm{ppm}$ polymer resulted in better oil recovery than the $200 \mathrm{ppm}$ polymer and that the tertiary polymer injection is more favorable compared to conventional formation water injection for about 6 PVs. The incremental oil recovery using tertiary polymer flooding is about 1.38 and $2.29 \%$ OOIP for 200 and $800 \mathrm{ppm}$ polymer concentration, respectively (Table 8 ).
Table 9 Prediction of secondary vs. tertiary polymer flooding using the UTCHEM simulator

\begin{tabular}{lcc}
\hline \multicolumn{3}{l}{ Secondary vs. tertiary polymer flooding (6 PVs of Injection) } \\
\hline Injection technique & Oil recovery (\%) & $\begin{array}{l}\text { Incremental } \\
\text { oil recovery } \\
(\%)\end{array}$ \\
\hline $\begin{array}{l}\text { Formation water flooding } \\
\text { Secondary polymer flooding } \\
\quad(800 \text { ppm })\end{array}$ & 65.14 & - \\
$\begin{array}{l}\text { Tertiary polymer flooding } \\
(800 \mathrm{ppm})\end{array}$ & 67.19 & 2.06 \\
\hline
\end{tabular}

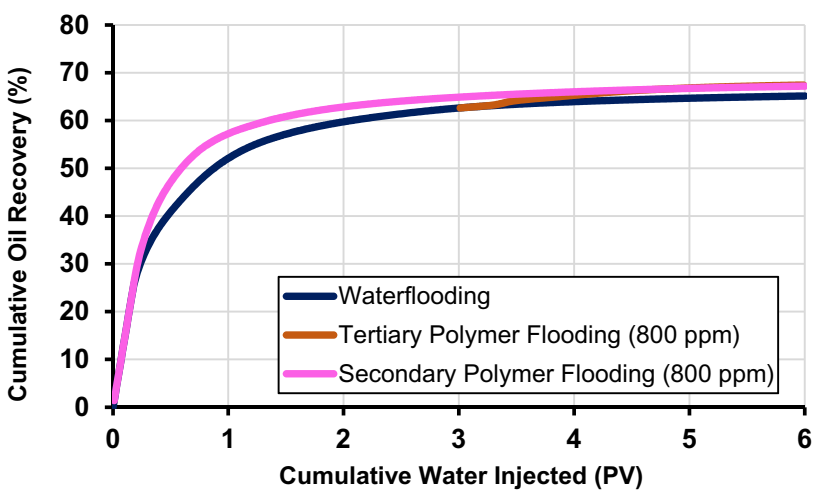

Fig. 23 Comparison between secondary vs. tertiary polymer flooding using $800 \mathrm{ppm}$ polymer concentration

\section{Biopolymer flooding comparison (secondary vs. tertiary injections)}

The results of Schizophyllan biopolymer injection in both secondary and tertiary modes of injection are shown in Table 9 as well as Fig. 23. The comparison was considered for polymer concentration of $800 \mathrm{ppm}$, which achieves the desired polymer viscosity of $10 \mathrm{cP}$ needed for reduction of water mobility and improvement of oil sweep efficiency.

The results show that in terms of cumulative oil recovery, both secondary and tertiary modes of polymer flooding are comparable as they result in about $2 \%$ incremental OOIP compared to conventional formation water injection. The latter makes sense as the biopolymer used does not have a viscoelastic effect and hence, it is not expected to decrease residual oil saturation. Nevertheless, secondary polymer injection is more favorable compared to tertiary polymer injection in terms of economics through early boosting oil production rate and achieving higher money time value. One should note that more experimental datasets are needed to further validate and generalize the results obtained in this study. 


\section{Summary and conclusions}

The performance of Schizophyllan biopolymer in carbonates with high temperature, high salinity, and low permeability conditions was successfully evaluated at core-scale. The following findings can be made based on the particular experimental dataset used in this work:

- Small-scale heterogeneity of the core is important in history matching formation water corefloods as well as in modeling polymer properties, particularly the shear effect on polymer viscosity.

- Formation permeability, polymer viscosity, and oil saturation maps should be consistent in justifying incremental oil recovery achieved by polymer flooding.

- The Schizophyllan biopolymer improves both displacement and volumetric sweep efficiencies through achieving favorable water fractional flow curve as well as endpoint mobility ratio compared to conventional waterflooding.

- Schizophyllan biopolymer improves oil recovery compared to conventional waterflooding through decreasing effective water permeability as well as increasing water viscosity, and hence reducing the water phase mobility.

- Secondary injection of Schizophyllan biopolymer is more favorable as opposed to tertiary injection due to boosting oil production rate at earlier time and hence, higher money time value.

- An optimum concentration of $800 \mathrm{ppm}$ is recommended for maintaining the desired polymer viscosity as well as achieving a minimum total relative mobility of oil and water phases.

In the future work, validation of polymer corefloods through considering different polymer datasets as well as field-scale studies will be considered to highlight the advantages of using Schizophyllan biopolymer on oil recovery from carbonate reservoirs. Moreover, sensitivity analysis as well as optimization studies will be performed.

Acknowledgements The author wishes to acknowledge Khalifa University of Science and Technology for the support and encouragement. This publication is partially supported by Khalifa University under Award No. [FSU-2018-26]. Moreover, the author would like to thank Professor Kamy Sepehrnoori at the University of Texas at Austin for providing access to UTCHEM.

Open Access This article is licensed under a Creative Commons Attribution 4.0 International License, which permits use, sharing, adaptation, distribution and reproduction in any medium or format, as long as you give appropriate credit to the original author(s) and the source, provide a link to the Creative Commons licence, and indicate if changes were made. The images or other third party material in this article are included in the article's Creative Commons licence, unless indicated otherwise in a credit line to the material. If material is not included in the article's Creative Commons licence and your intended use is not permitted by statutory regulation or exceeds the permitted use, you will need to obtain permission directly from the copyright holder. To view a copy of this licence, visit http://creativecommons.org/licenses/by/4.0/.

\section{References}

Adegbite JO, Al-Shalabi EW, Ghosh B (2018) Geochemical modeling of engineered water injection on oil recovery from carbonate cores. J Petrol Sci Eng 170:696-711

Al-Hashim H, Obiora V, Al-Yousef H, Fernandez F, Nofal W (1996) Alkaline surfactant polymer formulation for Saudi Arabian carbonate reservoirs. Paper SPE 35353, SPE improved oil recovery symposium, Tulsa, Oklahoma, USA.

Al-Shalabi EW (2014) Modeling the effect of injecting low salinity water on oil recovery from carbonate reservoirs. PhD Dissertation, The University of Texas at Austin, Texas, USA

Al-Shalabi EW, Sepehrnoori K (2016) A comprehensive review of low salinity/engineered water injections and their applications in sandstone and carbonate rocks. J Petrol Sci Eng 139:137-161

Al-Shalabi EW, Sepehrnoori K (2017) Low salinity and engineered water injection for sandstone and carbonate reservoirs. Gulf Professional Publishing, Elsevier, 1st edn, pp 178, ISBN: 9780-12-813604-1, Cambridge, USA.

Al-Shalabi EW, Sepehrnoori K, Pope GA (2015) New mobility ratio definition for estimating volumetric sweep efficiency of low salinity water injection. Fuel J 158:664-671

Al-Shalabi EW, Sepehrnoori K, Delshad M (2014a) Optimization of the low salinity water injection process in carbonate reservoirs. Paper SPE 17821, SPE international petroleum technology conference, Kuala Lumpur, Malaysia.

Al-Shalabi EW, Sepehrnoori K, Pope G, Mohanty K, (2014b) A fundamental model for prediction oil recovery due to low salinity water injection in carbonate rocks. Paper SPE 169911, SPE trinidad \& tobago energy resources conference, Port of Spain, Trinidad and Tobago

Austad T, Strand S, Madland MV, Puntervold T, Korsnes RI (2008) Seawater in chalk: an EOR and compaction fluid. Paper SPE 118431, SPE international petroleum technology conference, Dubai, UAE

Azad MS, Trivedi JJ (2019) Novel viscoelastic model for predicting the synthetic polymer's viscoelastic behavior in porous media using direct extensional rheological measurements. Fuel Journal 235:218-226

Bennetzen MV, Gilani SFH, Mogensen K, Ghozali M, Bounoua N (2014) Successful polymer flooding of low-permeability, oil-wet, carbonate reservoir cores. Paper SPE 171849, SPE ADIPEC, Abu Dhabi, UAE

Bondor PL, Hirasaki GJ, Tham MJ (1972) Mathematical simulation of polymer flooding in complex reservoirs. SPE J 12(5):369-382

Brooks RH, Corey AT (1966) Properties of porous media affecting fluid flow. J Irrig Drain Div 92(2):61-88

Cannella WJ, Huh C, Seright RS (1988) Prediction of xanthan rheology in porous media. Paper SPE 18089, SPE annual technical conference and exhibition, Houston, Texas, USA

Carter WH, Payton JT, Pindell RG (1980) Biopolymer injection into a low permeability reservoir. Paper SPE 8836, SPE symposium on enhanced oil recovery, Tulsa, Oklahoma, USA

Chandrasekhar S, Mohanty KK (2013) Wettability alteration with brine composition in high-temperature carbonate reservoirs. SPE annual technical conference and exhibition, New Orleans, Louisiana, USA 
Chang HL (1978) Polymer flooding technology-yesterday, today, and tomorrow. J Petrol Technol 30(8):1113-1128

Chiappa L, Mennella A, Lockhart TP, Burrafato G (1999) Polymer adsorption at the brine-rock interface: the role of electrostatic interactions and wettability. J Petrol Sci Eng 24(2-4):113-122

Dawson R, Lantz RB (1971) Inaccessible pore volume in polymer flooding. Paper SPE 3522, SPE annual fall meeting, New Orleans, Louisiana, USA

Delamaide E (2018) Polymers and their limits in temperature, salinity and hardness: theory and practice. SPE Asia Pacific oil and gas conference and exhibition. Paper SPE 192110, Brisbane, Australia

Diab WN, Al-Shalabi EW (2019) Recent developments in polymer flooding for carbonate reservoirs under harsh conditions. Paper SPE 29739, SPE Offshore Technology Conference, Rio de Janeiro, Brazil

Erincik M, Qi P, Balhoff MT, Pope GA (2018) New Method to reduce residual oil saturation by polymer flooding. Paper SPE 187230 . SPEJ 23:1994-1956

Flory PJ (1953) Principles of polymer chemistry. Cornell University Press

Goudarzi A, Delshad M, Sepehrnoori K (2013) A critical assessment of several reservoir simulators for modeling chemical enhanced oil recovery processes. Paper SPE 163578, SPE reservoir simulation symposium, Texas, USA

Green DW, Willhite PW (1998) Enhanced Oil Recovery. SPE Textbook Series, Richardson

Han M, Fuseni A, Zahrani B, Wang J (2014) Laboratory study on polymers for chemical flooding in carbonate reservoirs. Paper SPE 169724, SPE EOR conference at oil and gas West Asia, Muscat, Oman.

Huh C, Pope GA (2008) Residual oil saturation from polymer floods: laboratory measurements and theoretical interpretation. Paper SPE 113417, SPE improved oil recovery symposium, Tulsa, Oklahoma, USA

Kohler N, Chauveteau G (1981) Xanthan polysaccharide plugging behavior in porous media-preferential use of fermentation broth. JPT 33(2):349-358

Kulawardana EU, Koh H, Kim DH, Liyanage PJ, Upamali K, Huh C, Weerasooriya U, Pope GA (2012) Rheology and transport of improved EOR polymers under harsh reservoir conditions. Paper SPE 154294, SPE improved oil recovery symposium, Tulsa, Oklahoma, USA
Lakatos I, Lakatos-Szabo J, Toth J (1979) Factors influencing polyacrylamide adsorption in porous media and their effect on flow behavior. In: 3rd international conference on surface and colloid science symposium, Stockholm

Lake LW (1989) Enhanced oil recovery. Prentice Hall, Englewood Cliffs

Lee VB (2015) The development and evaluation of polymers for enhanced oil recovery. Master Thesis, The University of Texas at Austin, Texas, USA.

Li J (2015) Experimental investigation and simulation of polymer flooding in high temperature high salinity carbonate reservoirs. Master Thesis, Khalifa University of Science and Technology, Abu Dhabi, UAE.

Manrique EJ, Muci VE, Gurfinkel ME (2006) EOR field experiences in carbonate reservoirs in the United States. Paper SPE 100063, SPE improved oil recovery symposium, Tulsa, Oklahoma, USA.

Meter DM, Bird RB (1964) Tube flow of non-newtonian polymer solutions: part I laminar flow and rheological models. AlChE Journal 10(6):878-881

Needham RB, Doe PH (1987) Polymer flooding review. J Petrol Technol 39(12): 1503-1507

Pu W, Shen C, Wei B, Yang Y, Li Y (2017) A comprehensive review of polysaccharide biopolymers for enhanced oil recovery (EOR) from flask to field. J Ind Eng Chem 61:1-11

Qi P, Ehrenfried DH, Koh H, Balhoff MT (2017) Reduction of residual oil saturation in sandstone cores by use of viscoelastic polymer. SPEJ 22:447-458

Quadri SMR (2015) Identification and evaluation of polymers for EOR in High temperature, high salinity carbonate reservoir conditions. Master Thesis, Khalifa University of Science and Technology, Abu Dhabi, UAE.

Sheng JJ (2011) Modern chemical enhanced oil recovery-theory and practice. Gulf Publishing, Elsevier

Sorbie KS (1991) Polymer improved oil recovery. Blackie and Son, Glasgow

UTCHEM-9.0 Documentation, 2000. The University of Texas, Volume II, Texas, USA

Zhu Y, Lei M, Zhu Z (2015) Development and performance of saltresistant polymers for chemical flooding. Paper SPE 172784, SPE middle east oil and gas show and conference, Manama, Bahrain.

Publisher's Note Springer Nature remains neutral with regard to jurisdictional claims in published maps and institutional affiliations. 